\title{
Radiation Effects in TiNbN Coatings Induced by Impact of Low-Energy Helium, Krypton and Xenon Ions
}

\author{
S. Kislitsin ${ }^{a, b, *}$, I. IVANOV ${ }^{a}$, M. Zdorovets ${ }^{a, b}$ AND A. LARIONOV ${ }^{a}$ \\ ${ }^{a}$ Institute of Nuclear Physics, Ibragimov Str., 1, 050032, Almaty, Kazakhstan, \\ ${ }^{b}$ NRNU "MEPhI", Kashirskoe Avenue, 31, 119409, Moscow, Russia
}

\begin{abstract}
Effects of irradiation with low-energy helium, krypton, and xenon ions on the structural and mechanical properties of the TiNbN coatings on $12 \mathrm{Cr} 18 \mathrm{Ni} 10 \mathrm{Ti}$ steel substrates are studied. The samples with TiNbN coatings on stainless steel were prepared by magnetron sputtering technique using two magnetrons with sputtering targets of titanium and niobium. Irradiations with ${ }^{4} \mathrm{He}^{2+},{ }^{84} \mathrm{Kr}^{14+}$, and ${ }^{132} \mathrm{Xe}^{18+}$ ions were performed in the low-energy channel of the accelerator DC-60 with an energy of $20 \mathrm{keV} / \mathrm{charge}$ up to the fluence $1 \times 10^{16} \mathrm{~cm}^{-2}, 5 \times 10^{16} \mathrm{~cm}^{-2}$, and $1 \times 10^{17} \mathrm{~cm}^{-2}$. Structure, element composition, thickness, surface morphology, hardness, and corrosion resistance of the coatings were studied by X-ray diffractometry, Rutherford backscattering on nitrogen, scanning electron microscopy, atomic force microscopy, nanohardness and corrosion rate measurements. It was found that the TiNbN coating significantly exceeds Cr18Ni10Ti stainless steel in the entire range of studied properties, such as strength, corrosion resistance, and tendency towards blistering. In spite of structural and physical-mechanical properties degradation under ion irradiation, the TiNbN coating demonstrates good mechanical properties which are better than those of unirradiated steel Cr18Ni10Ti.
\end{abstract}

DOI: 10.12693/APhysPolA.136.356

PACS/topics: $61.80 . \mathrm{Lj}, 61.80 . \mathrm{Bg}$

\section{Introduction}

One of the trends for development of new structural materials for nuclear installations is the deposition on the existing structural materials of protective coatings with high stability of physical and mechanical properties against the effects of ionizing radiation. In particular, this applies to the Generation IV nuclear reactors, among which reactors with liquid metal coolants and gas-cooled reactors are considered as promising. In addition to the neutron flux, materials of such reactors can be exposed to high temperatures and corrosive environments.

Ternary transition metal nitrides (TiZrN, TiCrN, TiMoN) are characterized by high strength, corrosion resistance and can be regarded as promising materials [1-3]. However, stability of their properties under irradiation has been investigated insufficiently. There are only few papers dealing with the TiZrN, TiCrN, TiMoN coatings [4-5]. In this paper the effect of irradiation with low-energy alpha-particles, krypton, and xenon ions on the stability of physical and mechanical properties of TiNbN coatings is studied. These coatings demonstrated high strength and anticorrosion properties. Alpha-particles irradiation simulates accumulation of helium in structural materials due to nuclear reactions

* corresponding author; e-mail: skislitsin@mail.ru under neutron irradiation of reactor internals; krypton and xenon ions simulate the irradiation with nuclear fuel fission fragments.

\section{Samples preparation}

The samples of the TiNbN coatings on stainless steel were prepared by magnetron sputtering technique [6]. The stainless steel $12 \mathrm{Cr} 18 \mathrm{Ni} 10 \mathrm{Ti}$ plates with dimensions $15 \times 15 \times 1 \mathrm{~mm}$ were taken as substrates. Coatings were deposited from two magnetrons with sputtering targets made of titanium (Ti purity of $99.99 \mathrm{wt} \%$ ) and niobium (Nb purity of $99.95 \mathrm{wt} \%$, with a small admixture of tungsten). The power supplied to the sputtered cathodes was $100 \mathrm{~W}$ for niobium and $110 \mathrm{~W}$ for titanium. The substrates for coating were mounted on a rotating drum. In addition to steel substrates, monocrystalline silicon substrates were attached to the drum and the coatings were applied simultaneously to steel and silicon substrates under the same conditions. The nitrogen content in the plasma-forming gas mixture during coating deposition was $\sim 25 \%$. The thickness of the coating was controlled by the deposition time. As a result the samples with thickness of the TiNbN coating from $\sim 800$ to $900 \mathrm{~nm}$ were obtained. The thickness of the coatings was chosen from the following considerations: the projective range of $40 \mathrm{keV}$ alpha-particles, $280 \mathrm{keV} \mathrm{Kr}$ ions, and $360 \mathrm{keV}$ Xe ions should be considerably smaller of the coating thickness. The projective range of $40 \mathrm{keV} \alpha$-particles, $280 \mathrm{keV} \mathrm{Kr}$ ions, and $360 \mathrm{keV}$ Xe ions is $\sim 100 \mathrm{~nm}$ (SRIM calculations) and coating thickness satisfy these reqirements. 


\section{Experimental technique and irradiation procedure}

Crystal structure was determined by X-ray diffractometry (XRD), using a diffractometer Brucker D8 Edvance. Surface morphology and element composition was studied by scanning electron microscopy (SEM) on a microscope Jeol JSM-7500 FA with the attached Oxford Instruments equipment for energy dispersive X-ray microanalysis (EDX). Atomic force microscopy (AFM) was conducted using a microcope AIST-NT. Thickness of the coatings was measured by Rutherford backscattering (RBS) using $1.75 \mathrm{MeV} /$ nucleon nitrogen ions generated by the heavy ion accelerator DC-60. Hardness of coatings was measured by sclerometry (scratching) method with a scanning nanohardnessmeter NanoScan Compact [7]. Corrosion resistance was studied using a Gamry Instruments corrosion cell.

Irradiation with ${ }_{4} \mathrm{He}^{2+},{ }_{84} \mathrm{Kr}^{14+}$, and ${ }_{132} \mathrm{Xe}^{18+}$ ions was carried out on the low-energy channel of the accelerator DC-60 (INP branch in Astana) with an energy of $20 \mathrm{keV} /$ charge up to the fluences: $10^{16} \mathrm{~cm}^{-2}$, $5 \times 10^{16} \mathrm{~cm}^{-2}$, and $10^{17} \mathrm{~cm}^{-2}$ at ion energy: $40 \mathrm{keV}(\mathrm{He})$, $280 \mathrm{keV}(\mathrm{Kr})$, and $360 \mathrm{keV}(\mathrm{Xe})$. Irradiation temperature did not exceed $150^{\circ} \mathrm{C}$.

\section{Structure and properties of TiNbN coating before ion irradiation}

The phase composition of the coating was determined with X-ray difratometry by shooting in the BraggBrentano geometry. For the X-ray phase analysis the NbTiN coating was deposited on the silicon substrate to avoid superimposing the X-ray reflexes from steel and coating. Deposition of TiNbN coating on the silicon substrate was carried out simultaneously with the coatings deposition on a steel substrate. Diffractogram of coating is shown in Fig. 1.

Calculations of the lattice parameters showed that two compounds were formed: titanium nitride with dissolved niobium (the lattice parameter $\left.a_{\mathrm{TiN}(\mathrm{Nb})}=0.4344 \pm 0.0008 \mathrm{~nm}\right)$ and niobium nitride with dissolved titanium $\left(a_{\mathrm{NbN}(\mathrm{Ti})}=0.4370 \pm 0.0006 \mathrm{~nm}\right)$. As follows from the ratio of the intensities of the reflections from the formed nitrides the process of dissolving niobium in titanium nitride proceeds 4 times faster than that of dissolving titanium in niobium nitride. The TiNbN coating elemental composition determined by means of RBS and EDX has shown that element contents vary from 53 to 58 at.\% for niobium, from 25 to 26 at.\% for titanium, and from 16 to 21 at.\% for nitrogen (see Table I). A small content of tungsten in the coating should be also mentioned.

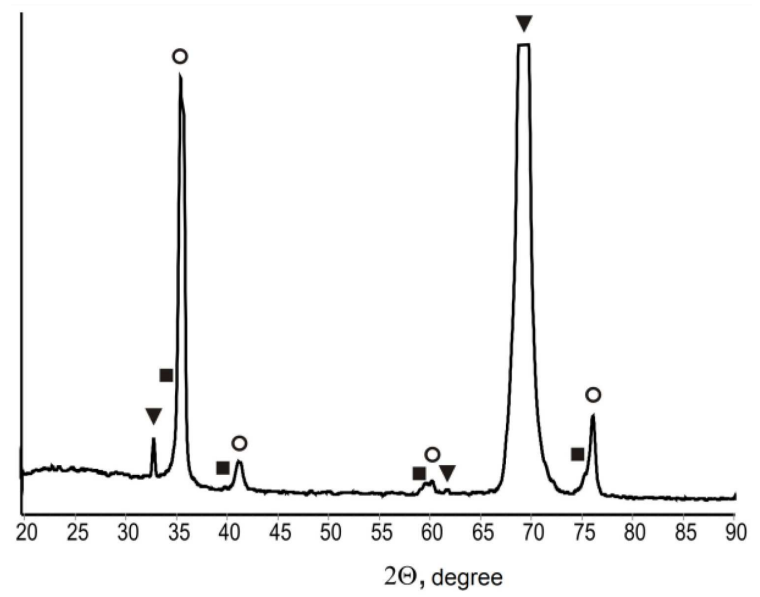

Fig. 1. Diffractogram of TiNbN coating on silicon substrate, which are marked by $\boldsymbol{\nabla}$ - Si substrate, - $\mathrm{NbN}$, ○- $\mathrm{TiN}$.

The surface structure is characterized by the presence of grains, the sizes of which are several tens of microns. In the grain body and at the boundaries there are inclusions ranging in size from tens to hundreds of nanometers (Fig. 2a). Apparently, the inclusions represent precipitations of the $\mathrm{NbN}$ phase with dissolved titanium as the amount of this phase in the coating is $\sim 4$ times smaller compare to the TiN phase with dissolved niobium (according to the X-ray diffractometry data).

Nanohardness value of the TiNbN coating is 24.1 GPa on a surface and decreases to $5.4 \mathrm{GPa}$ at a distance of $200 \mathrm{~nm}$ from the surface. These values exceed the nanohardness of stainless steel C0.12Cr18Ni10Ti substrate material many times $(4.4 \mathrm{GPa}$ on the surface and 1.7 $\mathrm{GPa}$ at $200 \mathrm{~nm}$ from the surface).

The corrosion resistance of the TiNbN coating is much better that of $12 \mathrm{Cr} 18 \mathrm{Ni} 10 \mathrm{Ti}$. The corrosion rate of TiNbN is $22 \times 10^{-6} \mathrm{~mm} /$ year, while the value for steel is $9 \times 10^{-3} \mathrm{~mm} /$ year.

Element composition of TiNbN coating before and after irradiation with low-energy He, $\mathrm{Kr}$ and Xe ions.

TABLE I

\begin{tabular}{c|c|c|c|c|c|c}
\hline \hline & $\begin{array}{c}\text { Unirrad. } \\
\text { [at.\%] }\end{array}$ & $\begin{array}{c}F=10^{17} \mathrm{~cm}^{-2} \\
\text { [at.\%] }\end{array}$ & $\begin{array}{c}\text { Unirrad. } \\
\text { [at.\%] }\end{array}$ & $\begin{array}{c}\mathrm{Kr}, \\
=10^{17} \mathrm{~cm}^{-2} \\
{[\text { at.\%] }}\end{array}$ & $\begin{array}{c}\text { Unirrad. } \\
\text { [at.\%] }\end{array}$ & $\begin{array}{c}\text { Xe, } \\
=10^{17} \mathrm{~cm}^{-2} \\
{[\text { at.\%] }}\end{array}$ \\
\hline $\mathrm{Nb}$ & 59.3 & 58.6 & 58.4 & 55.8 & 60.9 & 52.8 \\
$\mathrm{Ti}$ & 29.3 & 26.8 & 29.5 & 27.6 & 25.6 & 25.6 \\
$\mathrm{~N}$ & 11.4 & 4.2 & 12.1 & 2.5 & 13.5 & 8.7 \\
$\mathrm{C}$ & 0.0 & 10.4 & 0.0 & 14.1 & 0.0 & 13.0
\end{tabular}



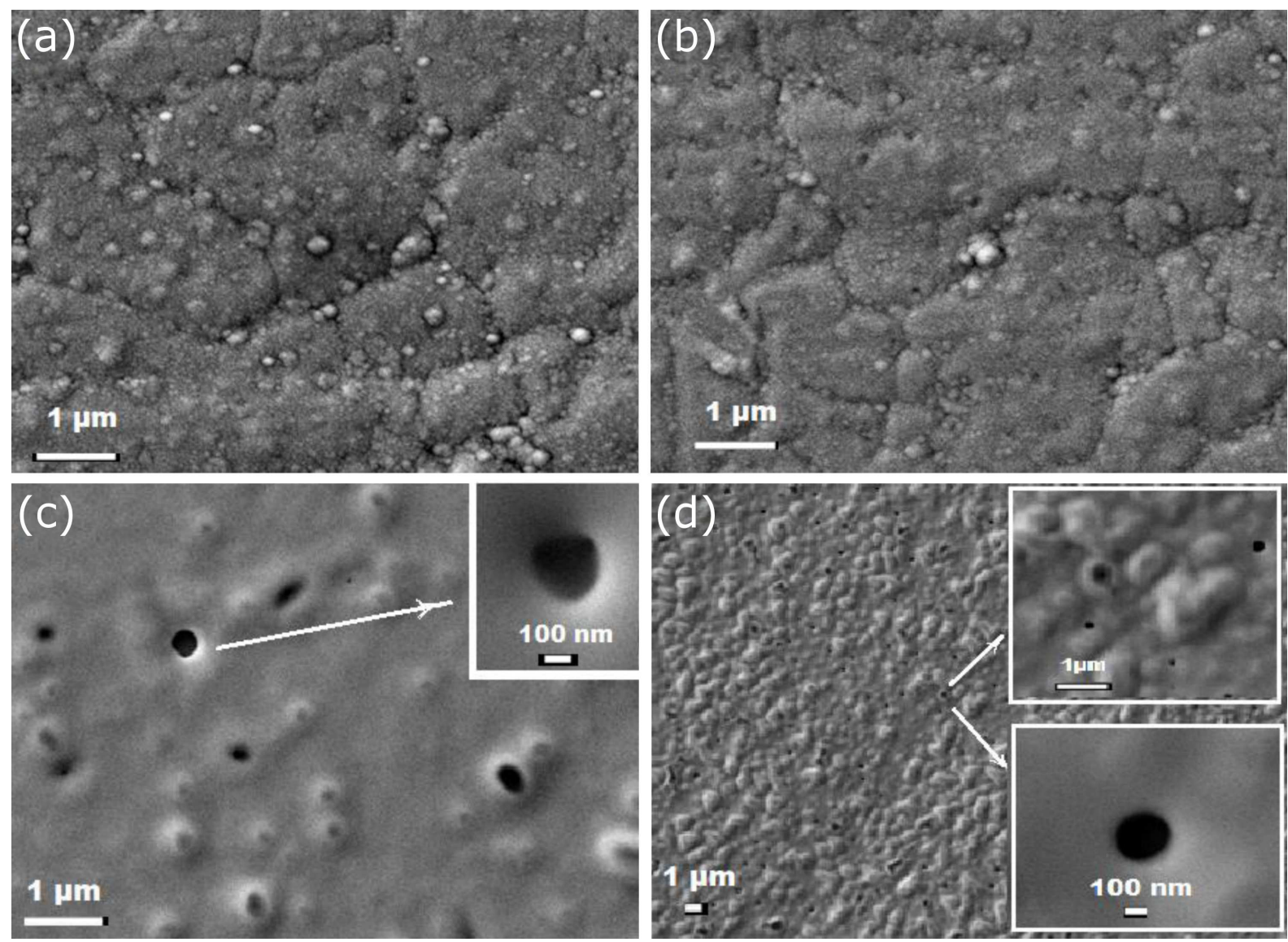

Fig. 2. SEM images of surface structure of TiNbN coating: (a) - before irradiation, (b) - after irradiation with $40 \mathrm{keV}$ He ions, $F=10^{17} \mathrm{~cm}^{-2}$, (c) - after irradiation with $280 \mathrm{keV} \mathrm{Kr}$ ions, $F=10^{17} \mathrm{~cm}^{-2}$, (d) - after irradiation with $360 \mathrm{keV}$ Xe ions, $F=10^{17} \mathrm{~cm}^{-2}$.

\section{Structure and properties of TiNbN coating irradiated with low-energy $\mathrm{He}, \mathrm{Kr}$ and $\mathrm{Xe}$ ions}

Ion irradiation has a multifaceted effect on the properties of solids. In this paper the influence of ion irradiation on the mechanical characteristics of the NbTiN coating is investigated. The main effects causing changes of mechanical properties under ion irradiation are:

- surface sputtering

- changes of surface structure

- degradation of physio-mechanical properties, such as hardness and corrosion resistance.

The above aspects of ion irradiation influence on structural and mechanical properties of the TiNbN coatings will be discussed below.

\subsection{Surface sputtering}

Surface sputtering upon irradiation with low-energy heavy ions is a well-known and rather thoroughly studied phenomenon [8-9]. However, in the case of the TiNbN compound it was not previously experimentally studied. This paper presents measurements of the TiNbN compound sputtering yield at bombardment by $\mathrm{Kr}$ and $\mathrm{Xe}$ ions with the energy $280 \mathrm{keV}$ and $360 \mathrm{keV}$, respectively. The sputtering yield was determined from the change in the TiNbN coating thickness due to ion irradiation. Coating thickness measurements was performed using the RBS method. The RBS spectra of TiNbN coating before and after irradiation by $280 \mathrm{keV} \mathrm{Kr}$ and $360 \mathrm{keV}$ Xe ions are shown in Fig. 3.

The results of sputtered TiNbN layers measurements, and experimentally determined sputtering yields for $\mathrm{Kr}$ and Xe ions together with sputtering yields calculated by SRIM are presented in Table II. As can be seen from Table II there is evidently a discrepancy between the experimentally measured data of sputtering yield for $\mathrm{Kr}$ and Xe ions and those calculated by SRIM.

It was not possible to measure the thickness of sputtered TiNbN layer by the RBS method after irradiation with helium ions. The thickness of sputtered layer upon irradiation by helium ions with the energy of $40 \mathrm{keV}$ up to the fluence of $10^{17} \mathrm{~cm}^{-2}$ is $\sim 2 \mathrm{~nm}$. In fact, it is lower than the accuracy of $\sim 5 \mathrm{~nm}$ of determining the coating thickness by RBS. It should be noted that the sputtering yield of TiNbN is of the same order as that of steel. 

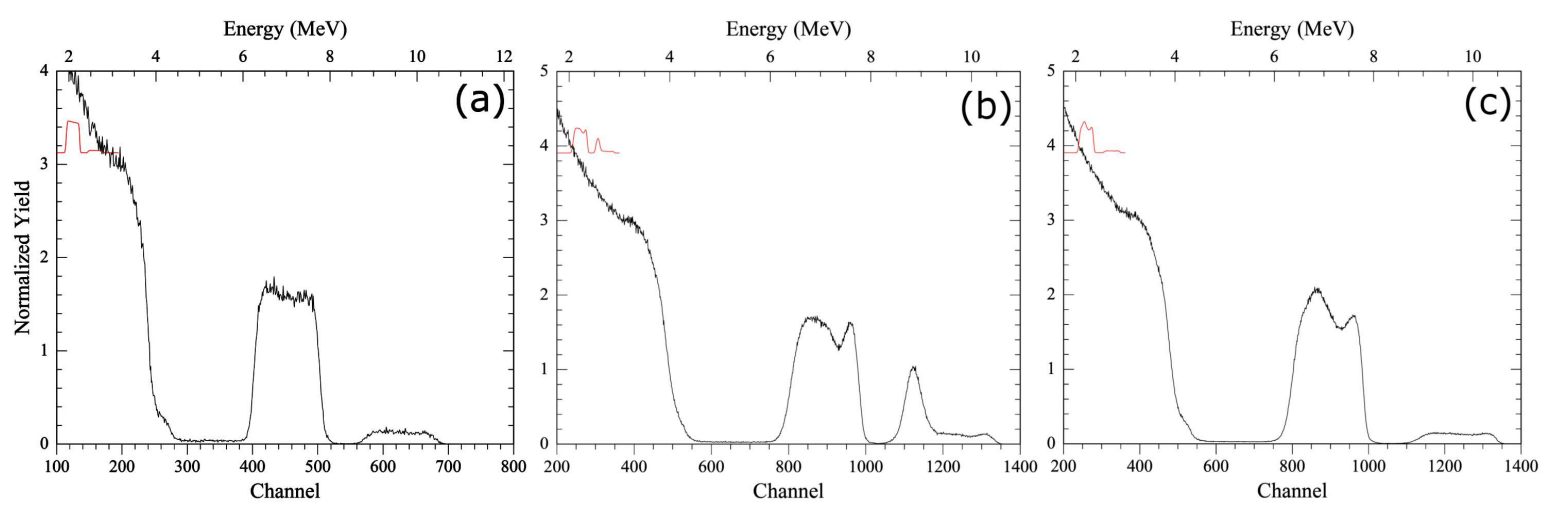

Fig. 3. RBS spectra of samples with TiNbN coating and their approximations: (a) - sample before irradiation, (b) - sample after irradiation, with $280 \mathrm{keV} \mathrm{Kr}$ ions, $F=10^{17} \mathrm{~cm}^{-2}$, (c) - sample after irradiation, with $360 \mathrm{keV} \mathrm{Xe}$ ions, $F=10^{17} \mathrm{~cm}^{-2}$.

TABLE II

Thickness of TiNbN coatings before and after irradiation, and experimentally obtained sputtering yield of TiNbN upon irradiation by low energy $\mathrm{Kr}$ and Xe ions.

\begin{tabular}{|c|c|c|c|c|c|c|c|}
\hline $\begin{array}{c}\text { Thickness } \\
\text { before } \\
\text { irradiation } \\
h_{1}[\mathrm{~nm}]\end{array}$ & $\begin{array}{c}\text { Thickness } \\
\text { after } \\
\text { irradiation } \\
h_{1}[\mathrm{~nm}]\end{array}$ & $\begin{array}{c}\text { Thickness } \\
\text { of sputtered } \\
\text { layer } \\
h_{1}-\mathrm{h}_{2}[\mathrm{~nm}]\end{array}$ & Ion & $\begin{array}{c}\text { Ion } \\
\text { energy } \\
{[\mathrm{keV}]}\end{array}$ & $\begin{array}{r}\text { Fluence } \\
{\left[\mathrm{cm}^{-2}\right]}\end{array}$ & $\begin{array}{c}\mathrm{Ks} \\
\text { [at./ion] }\end{array}$ & $\begin{array}{c}\mathrm{Ks}^{*} \\
\text { [at./ion] }\end{array}$ \\
\hline 920 & 910 & 10 & ${ }^{84} \mathrm{Kr}^{+14}$ & 280 & $1 \times 10^{16}$ & 5.4 & \\
\hline 880 & 840 & 40 & ${ }^{84} \mathrm{Kr}^{+14}$ & 280 & $5 \times 10^{16}$ & 4.3 & 4.1 \\
\hline 920 & 820 & 100 & ${ }^{84} \mathrm{Kr}^{+14}$ & 280 & $1 \times 10^{17}$ & 5.4 & \\
\hline 870 & 860 & 10 & ${ }^{132} \mathrm{Xe}^{+18}$ & 360 & $1 \times 10^{16}$ & 5.4 & \\
\hline 920 & 870 & 50 & ${ }^{132} \mathrm{Xe}^{+18}$ & 360 & $5 \times 10^{16}$ & 5.4 & 5.2 \\
\hline 920 & 790 & 130 & ${ }^{132} \mathrm{Xe}^{+18}$ & 360 & $1 \times 10^{17}$ & 7.6 & \\
\hline
\end{tabular}

\subsection{Changes of surface structure}

The surface structure undergoes substantial changes under the action of irradiation with low-energy ions (Fig. 2). This is particularly evident upon irradiation with heavy $\mathrm{Kr}$ and Xe ions, as can be seen in the surface images in Fig. 2c and d.

Irradiation with He ions leads to minimal changes of TiNbN surface compared to that by $\mathrm{Kr}$ and $\mathrm{Xe}$ ions. The most significant change induced by He ions bombardment consists of decreasing sizes and number of small inclusions which, apparently, are the precipitates of $\mathrm{NbN}$ phase with dissolved titanium (Fig. 2b). Presumably, upon the alpha-particle irradiation, dissolution of these inclusions takes place.

Irradiation with $\mathrm{Kr}$ ions leads to more significant changes of structure. Besides inclusions dissolution, at the fluence of $10^{16} \mathrm{~cm}^{-2}$, formation of the hillocks on the coating surface is observed. With increasing fluence to $F=5 \times 10^{16} \mathrm{~cm}^{-2}$ craters appear on the surface and at the fluence of $10^{17} \mathrm{~cm}^{-2}$ the hillocks become open to the surface with the holes in its center (Fig. 2c).

The most significant changes of surface structure appear upon irradiation with Xe ions. At the fluence of $10^{16} \mathrm{~cm}^{-2}$ separate craters are observed on the coating surface. With the fluence increased to $5 \times 10^{16} \mathrm{~cm}^{-2}$ a coral like structure begins to form. At the fluence of $10^{17} \mathrm{~cm}^{-2}$ a coral like structure with holes in the hillocks centers is observed (Fig. 2d).

In spite of sputtering and changes of TiNbN surface structure, the element composition of coating does not change significantly (Table II). The appearance of carbon on surface should be noted.

\subsection{Degradation of physical-mechanical properties}

Hardness of TiNbN coating was measured by the sclerometry (scratching) method using the scanning nanohardnessmeter "NanoScan Compact". Using this device, it is possible to measure the hardness from different depths of material by changing the load on the indenter and hence, depth of penetration of the indenter. In such way the hardness of unirradiated and irradiated TiNbN coating was measured. It follows from the results of implemented measurements that after the irradiation to the fluence of $10^{16} \mathrm{~cm}^{-2}$ with $\mathrm{He}, \mathrm{Kr}$, and Xe ions hardness of surface layers increases $2-3$ times. With the fluence growth hardness of surface layers decreases and at the fluence of $10^{17} \mathrm{~cm}^{-2}$ becomes smaller than that of unirradiated TiNbN. The hardness of TiNbN irradiated with Xe ions is smaller than that after irradiation by He and Kr ions, as shown in Fig. 4. 


\begin{tabular}{l|c|c|c}
\hline \multicolumn{1}{c|}{ Material } & \multicolumn{3}{|c}{ Corrosion parameters } \\
\cline { 2 - 4 } & $I_{\text {corr }}[\mathrm{nA}]$ & $E_{\text {corr }}[\mathrm{mV}]$ & $V_{\text {corr }}[\mathrm{mm} /$ year $]$ \\
\hline Steel 12Cr18Ni10Ti - unirradiated & 946 & -359 & $9 \times 10^{-3}$ \\
TiNbN - unirradiated & $868 \times 10^{-3}$ & -156 & $22 \times 10^{-6}$ \\
TiNbN $-{ }^{84} \mathrm{Kr}^{+14}, E=280 \mathrm{keV}, F=5 \times 10^{16} \mathrm{~cm}^{-2}$ & 3 & -147 & $63 \times 10^{-6}$ \\
TiNbN $-{ }^{132} \mathrm{Xe}^{+18}, E=360 \mathrm{keV}, F=5 \times 10^{16} \mathrm{~cm}^{-2}$ & 33 & -159 & $820 \times 10^{-6}$
\end{tabular}

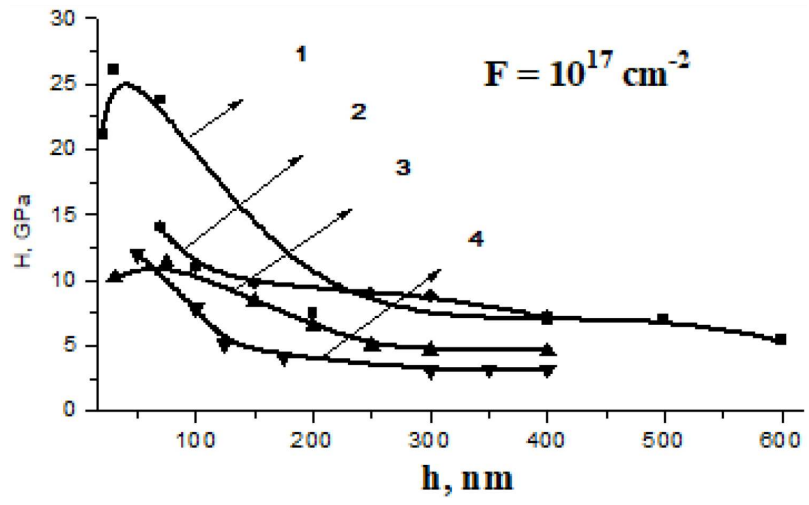

Fig. 4. Hardness of TiNbN coating after irradiation to ion fluence $10^{17} \mathrm{~cm}^{-2} ; 1$ - for unirradiated TiNbN coating, 2 - after irradiation with He ions, 3 - after irradiation with $\mathrm{Kr}$ ions, 4 - after irradiation with Xe ions.

The reason for the decrease in the surface hardness is evidently strong atomization of the surface by krypton and xenon ions. In the case of irradiation with xenon ions, the thickness of the atomized layer is comparable to the projected range and the implanted xenon is sputtered together with the coating.

Tests on the corrosion resistance of unirradiated stainless steel $12 \mathrm{Cr} 18 \mathrm{Ni} 10 \mathrm{Ti}$ and unirradiated and irradiated TiNbN coatings were carried out in the $3 \% \mathrm{NaCl}$ solution. The tests results are presented in Table III.

Deterioration of corrosion properties is due to the formation of craters on the surface during irradiation by $\mathrm{Kr}$ and Xe ions. However, as can be seen from Table III, the corrosion resistance of the coating irradiated with heavy ions to fluence of $5 \times 10^{16} \mathrm{~cm}^{-2}$ is significantly higher than that of unirradiated steel.

\section{Conclusion}

The results of experimental studies on low-energy helium, krypton, and xenon ions regarding irradiation influence on the structure and physico-mechanical properties of TiNbN coatings can be formulated as follows:

1. Using magnetron sputtering technique the samples with the TiNbN coatings on stainless steel were prepared. It was found that the TiNbN coatings significantly exceed Cr18Ni10Ti stainless steel in the entire range of studied properties, such as hardness, corrosion resistance, and tendency to blistering. Sputtering yields of the TiNbN coatings under bombardment by $280 \mathrm{keV} \mathrm{Kr}$ and $360 \mathrm{keV}$ Xe ions were experimentally evaluated.

2. Irradiation with $\mathrm{Kr}$ ions leads to formation of the hillocks on the coating surface. With the fluence increased up to $10^{17} \mathrm{~cm}^{-2}$ the hillocks became open to the surface with holes in its centre. At irradiation with Xe ions formation of a coral-like structure with holes in hillocks centers is observed.

Physical-mechanical properties of the TiNbN coatings degrade upon low-energy ion irradiation but exceed substantially the properties of unirradiated stainless steel Cr18Ni10Ti.

\section{Acknowledgments}

The investigations were performed in the framework of the grant \#AP05133476 of the Ministry of Education and Science RK.

\section{References}

[1] A.L. Ivanovskii, Chem. Progress 65, 499 (1996) (in Russian).

[2] V.V. Uglov, V.M. Anischik, S.V. Zlotski, G. Abadias, S.N. Dub, Sur. Coat. Technol. 200, 178 (2005).

[3] A. Ciriello, V.V. Rondinella, D. Staicu, J. Somers, J. Nucl. Mater. 371, 129 (2007).

[4] V.V. Uglov, D.P. Rusalski, S.V. Zlotski, A.V. Sevriuk, G. Abadias, S.B. Kislitsin, K.K. Kadyrzhanov, I.D. Gorlachev, S.N. Dub, Sur. Coat. Technol. 204, 2095 (2010).

[5] S. Kislitsin, V. Uglov, A. Larionov, AIP Conf. Proc. 1783, 020091 (2016).

[6] Y. Tuleushev, V. Volodin, E. Zhakanbaev, Vestnik National Nuclear Center of RK N1, 18 (2007).

[7] NanoScan, NanoScan Compact.

[8] Sputtering by Particle Bombardment. I Physical Sputtering Single-Element Solids, Eds. R. Berisch, Springer-Verlag, Berlin-Heidelberg-New York, 1981.

[9] Sputtering by Particle Bombardment. II Sputtering Alloys and Compounds, Electron and Neutron Sputtering, Surface Topography Eds. R. Berisch, SpringerVerlag, Berlin-Heidelberg-New York, 1983. 